\title{
Jean-Bernard Vray, Le «paysage fer» de François Bon
}

\section{Rosa Galli Pellegrini}

\section{(2) OpenEdition}

\section{Journals}

\section{Edizione digitale}

URL: http://journals.openedition.org/studifrancesi/33717

DOI: 10.4000/studifrancesi.33717

ISSN: 2421-5856

\section{Editore}

Rosenberg \& Sellier

\section{Edizione cartacea}

Data di pubblicazione: 1 décembre 2005

Paginazione: 680

ISSN: 0039-2944

\section{Notizia bibliografica digitale}

Rosa Galli Pellegrini, «Jean-Bernard Vray, Le «paysage fer» de François Bon», Studi Francesi [Online], 147 (XLX | III) | 2005, online dal 30 novembre 2015, consultato il 20 avril 2021. URL: http://

journals.openedition.org/studifrancesi/33717 ; DOI: https://doi.org/10.4000/studifrancesi.33717

\section{Questo documento è stato generato automaticamente il 20 avril 2021.}

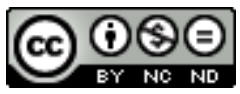

Studi Francesi è distribuita con Licenza Creative Commons Attribuzione - Non commerciale - Non opere derivate 4.0 Internazionale. 


\title{
Jean-Bernard Vray, Le «paysage fer» de François Bon
}

\author{
Rosa Galli Pellegrini
}

\section{NOTIZIA}

JEAN-BERNARD VRAY, Le «paysage fer» de François Bon in Le génie du lieu. Des paysages en littérature, sous la direction d'Arlette Bouloumié et d'Isabelle Trivisani-Moreau, Imago, 2005, pp. 340-351

1 Romanziere ai suoi inizi, François Bon passa al récit dopo il 1990, con L'Enterrement; a fare da cardine a questo cambiamento di orientamento scritturale si delinea Paysage fer del 2000. L'A. si addentra nelle occasioni e nelle modalità della stesura di questo testo, a partire da foto scattate e da note manoscritte redatte durante i viaggi in ferrovia. L'organizzazione della scrittura, che tiene anche conto del fattore "velocità" del mezzo di trasporto, rientra nelle esperienze di un genere già collaudato (Depardon, Plossu), ma, piuttosto che l'erranza, Bon privilegia il fattore della "ripetitività" che lo porta a scrivere in contemporanea con la visione fuggitiva. Nasce così un'opera che esplora la "geografia umana" del territorio. 